\title{
A platform technology of recovery of lactic acid from a fermentation broth of novel substrate Zizyphus oenophlia
}

\author{
Moumita Bishai - Swarnalok De $\cdot$ \\ Basudam Adhikari · Rintu Banerjee
}

Received: 2 May 2014 / Accepted: 19 July 2014/ Published online: 22 August 2014

(c) The Author(s) 2014. This article is published with open access at Springerlink.com

\begin{abstract}
Lactic acid, a biologically derived compound, exists ubiquitously in nature. Its existence ranges from human being to microorganisms. Having paramount industrial significance, lactic acid should be highly pure, devoid of any contaminants. Hence, development of minimum steps of platform technologies to purify it needs urgent attention. The article proposed a novel and simple process for separation of lactic acid from a potential substrate Zizyphus oenophlia, based on ion exchange chromatography. The process herein involves two steps of purification; firstly a weak anion exchange resin was used to separate lactic acid from other anions present in the broth. This was followed by use of strong cation exchanger which washes out the target molecule (lactic acid) while trapped other cations present in the solution. The selected ion exchangers were Amberlite IRA 96 and Amberlite IR 120. Amberlite IRA 96 retained the lactic acid from the broth while washing away other anions. Maximum binding capacity of the resin was found to $210.46 \mathrm{mg}$ lactic acid/g bead. After the simple two-step purification process, the purity of lactic acid improves up to $99.17 \%$ with a recovery yield of $98.9 \%$. Upon characterization, formation of only levo rotatory form of lactic acid confirms its easy metabolism by the human system, thus triggering its application towards biomaterial sector.
\end{abstract}

M. Bishai · S. De $\cdot$ R. Banerjee $(\bowtie)$

Microbial Biotechnology and Downstream Processing Laboratory, Agricultural and Food Engineering Department, Indian Institute of Technology, Kharagpur 721 302, India e-mail: rb@iitkgp.ac.in

B. Adhikari

Materials Science Centre, Indian Institute of Technology, Kharagpur 721 302, India
Keywords Lactic acid - Purification - Ion exchange resin · Amberlite IRA 96 - Amberlite IR 120

\section{Introduction}

Chemical industries are undergoing a transition in their orientation from conventional chemical production to biotechnological production. One of the main aspects of biotechnological process development, which is considered during the production and purification of valuable biomolecules, is tailoring of the bioseparation techniques specifically for isolating the targeted product to impart improved resolution, simplicity, selectivity along with easy scaling up of the process (Tong et al. 2004; Negi et al. 2011). Biotechnologically formed products are known for more than a century and are used in different industrial sectors. Lactic acid is one such product which finds its application in multitude sector. It is produced from varied range of carbohydrate-rich renewable resources using fermentation technology (Wee et al. 2006; Bishai et al. 2013a). It can be metabolized by the human system due to the presence of L-lactate dehydrogenase inside the body which triggers its application in biomaterial sector. $\mathrm{L}(+)$ lactic acid is the raw material for the production of polylactic acid (PLA) (Bishai et al. 2013b). To obtain highquality polylactic acid, $\mathrm{L}(+)$ Lactic acid with high purity is the prerequisite. The purification of lactic acid from the aqueous fermentation broth remains a problem considering its purity, recovery and cost of purification.

A variety of different downstream processing methods like precipitation with calcium hydroxide, electrodialysis, crystallization, extraction, etc. have been reviewed recently for purification(Kaufman et al. 1995; Madzingaidzo et al. 2002; Pal et al. 2009; Gonzalez et al. 2007). Most of these 
separation technologies have either shown low selectivity or low recovery yield. Crystallization for example demonstrated high selectivity, yet, its low recovery of mother liquor restrained its application for large-scale purpose (Caboche et al. 2000). Hence, the propensity for chromatographic techniques rose due to its low cost, high selectivity and ease of operation (Sosa et al. 2000). Among the various categories of chromatographic techniques, ion exchange chromatography for integrative purification has been developed to diminish the overall time required for conventional downstream processing and increase the product yield. Its other advantages include requirement of low cost raw material, execution in shorter time period, moderate operational conditions and generation of minimum amount of wastes (Raya-Tonetti et al. 1998). Considering ion exchange chromatography, several kinds of ion exchangers (Zheng et al. 1996; Chol and Hong 1999; Cao et al. 2002) have been studied on the recovery of lactic acid in the past few years. To successfully design the purification processes, it is of utmost importance to investigate and accordingly adjust the process parameters like selection of the resin, efficiency of binding, adjustment of elution conditions, etc. in a way, to selectively isolate the molecule of interest among all the other contaminants.

The present investigation concentrated on reduction of the steps of purification process, which may lessen its production cost and percentage loss. Two-step separation techniques to purify lactic acid from the fermentation broth including anion and cation exchange chromatography were performed. Amberlite IRA 96 and Amberlite IR 120, containing styrene-divinyl benzene matrix with polyamine functional group and sulfonic acid, respectively, as the active group, were considered for the present study. The binding capacity, breakthrough curve, elution condition, flowthrough and washing condition during purification process for lactic acid were described. Moreover, other parameters in terms of recovery percentage, purity, etc. were also considered for justifying the process.

\section{Methods}

Fermentation of lactic acid

Zizyphus oenophlia was used as a substrate for lactic acid fermentation using Lactobacillus amylophilus GV6. Modified de Man, Rogosa and Sharpe (MRS) medium and substrate ratio of $3: 2$, inoculum volume of $3 \%$ at $35{ }^{\circ} \mathrm{C}$ and $\mathrm{pH} 6.5$ for $96 \mathrm{~h}$ having $0.7 \% \mathrm{CaCO}_{3}$ were optimized conditions for fermentation which resulted in $95.09 \%$ conversion to lactic acid (Bishai et al. 2013a). After fermentation, the characteristics of the fermented broth includes L-isomeric form of lactic acid having concentration of $200 \mathrm{mg} / \mathrm{ml}, \mathrm{pH} \mathrm{1-2}$ and residual sugar content $0.86 \%$.

After fermentation, the fermented broth was centrifuged at $8,000 \times g$ for $20 \mathrm{~min}$. The supernatant obtained from the extract of fermented broth was used for lactic acid estimation according to the Kimberley and Taylor (1996) method.

The supernatant obtained after centrifugation was subjected to ultrafiltration (Vivascience, USA) using a membrane of 10,000 molecular weight cut off. The permeate portion collected after ultrafiltration was used for purification.

\section{Ion exchange resin preparation}

Amberlite IRA 96 (Sigma Aldrich, USA) and Amberlite IR-120 (Sigma Aldrich, USA), as anion and cation exchangers, respectively, were selected for the particular study. Both the resins comply with the legislation on food product uses. Amberlite IRA 96 is a weakly basic anion exchange resin with an unusually high capacity for large organic acids. Before utilization, the resin was washed and converted into their $\mathrm{Cl}^{-}$form as it could not be obtained in $\mathrm{OH}^{-}$form (resin remained in free base form at $\mathrm{pH}$ higher than 9) (John et al. 2008). Resins in $\mathrm{Cl}^{-}$form were obtained by washing the resins sequentially with $1 \mathrm{~N} \mathrm{HCl}$ solution, distilled water, $1 \mathrm{~N} \mathrm{NaOH}$ solution, distilled water, $1 \mathrm{~N} \mathrm{HCl}$ solution and distilled water (until $\mathrm{pH}$ 7). Similarly, Amberlite IR-120 was regenerated to $\mathrm{H}^{+}$form by washing with $1 \mathrm{~N} \mathrm{HCI}$, and thoroughly rinsed with distilled water (Rincon et al. 2007).

\section{Effect of $\mathrm{pH}$ of fermented broth on lactic acid binding}

$25 \mathrm{~g}$ of resin of IRA 96 and $150 \mathrm{~mL}$ of ultrafiltrated lactic acid broth at different initial pHs $(2,3,4,5,6,7,8,9,10)$ adjusted with $\mathrm{NaOH}$ were taken in a conical flask and kept for shaking. After $12 \mathrm{~h}$, samples of the supernatants were withdrawn and analyzed for lactic acid. $\mathrm{pH}$ for maximum lactic acid binding was determined by comparing the percentage of lactic acid from the fermentation broth that had adsorbed to the resin in each case.

Binding capacity of the resin

In the current study, $25 \mathrm{~g}$ of IRA 96 resin and $25 \mathrm{~mL}$ of ultrafiltrated lactic acid broth of different concentrations $(10,25,50,75,100,150,200,250 \mathrm{mg}$ lactic acid/mL) were mixed for direct contact in $100 \mathrm{~mL}$ flasks at $25{ }^{\circ} \mathrm{C}$ and kept in a mechanical shaker. After $12 \mathrm{~h}$, samples of the supernatants were withdrawn and analyzed for lactic acid through HPLC. Residual lactic acid concentrations in the solutions were measured and the amount of lactic acid adsorbed per gram resin was calculated. 
Breakthrough curve determination

A column (length, $20 \mathrm{~cm}$; i.d., $1.6 \mathrm{~cm}$ ) packed with $\sim 25 \mathrm{~g}$ resin was used for column separation. The column was washed with water after the resin was regenerated. After adjustment of desired $\mathrm{pH}$, ultrafiltrated sample of lactic acid was applied on the column at a flow rate of $0.8 \mathrm{~mL} /$ min. Eluate was collected and the lactic acid concentration was measured by HPLC.

Effect of different normality of $\mathrm{HCl}$ on the elution profile of lactic acid

In this study, $\mathrm{HCl}$ of different normality $(0.05,0.1,0.25$, $0.5,0.75$ and $1 \mathrm{~N}$ ) was added as eluent to $\sim 25 \mathrm{~g}$ of lactic acid loaded resin, packed in ion exchange column. All the fractions containing lactic acid in eluate were pulled together in each case and analyzed for concentration and percentage purity of lactic acid.

Effect of washing capacity of the cationic resin

Fractions containing lactic acid in the eluate after purification through anion exchange were collected and adjusted at different $\mathrm{pH}(2,3,4,5,6$, and 7) with $\mathrm{NaOH}$. The individual fractions were fed to the ion exchange column packed with $\sim 25 \mathrm{~g}$ of IR 120 resin which is cationic in nature. To remove the contaminations left after first step of ion exchange, this technique of negative chromatography was adapted, where the contaminants were selectively retained in the column and lactic acid is obtained in the flow-through or in the washing steps.

Analysis of lactic acid through high performance liquid chromatography (HPLC)

Concentration and purity of lactic acid were analyzed by HPLC system with UV-VIS detector at $210 \mathrm{~nm}$. Zorbax $\mathrm{C}^{18}$ column $(4.6 \times 250,5 \mu \mathrm{m})$ was used with a mobile phase of $0.1 \mathrm{M}$ orthophosphoric acid. The flow rate was fixed at $0.75 \mathrm{~mL} / \mathrm{min}$ and the injection volume was $20 \mu \mathrm{l}$. The concentration and percentage purity of lactic acid in eluate were determined from the peak area and number of peaks.

\section{Characterization of lactic acid}

$\mathrm{UV}-\mathrm{V}$ is spectrophotometer

Spectral analysis was performed through spectrophotometer UV-Vis spectrophotometer (Agilent technologies, USA). Purified lactic acid was taken separately in quartz cuvette and absorption spectrum was determined over a range of 205-700 $\mathrm{nm}$ wavelengths. The method was performed according to Guo et al. (2012).

Circular dichroism (CD) spectropolarimeter

Circular dichroism spectropolarimeter JASCO (J-810) with optical activity at $25{ }^{\circ} \mathrm{C}$, wavelength of $210 \mathrm{~nm}$ and a concentration of $1 \mathrm{~g} / \mathrm{dL}$ in chloroform has been used to measure the enantiomeric purity of the samples with excellent precision. The specific optical rotation of purified lactic acid was measured at $25{ }^{\circ} \mathrm{C}$ using Circular dichroism spectropolarimeter within a range of 190-280 nm wavelength. L-Acids show a positive whilst the D-isomers show a negative effect in the range of 220-230 $\mathrm{nm}$ according to Gargely and Polarimetry (2000). By comparing with standard L-lactic acid, the optical purity of the products was confirmed.

\section{Results}

Initial purification by centrifugation and ultrafiltration

Centrifugation of the fermented broth was the preliminary step performed prior to the main purification process. The validation and efficiency of the step were observed through the HPLC profile of the supernatant of centrifugation (Fig. 5). Relative purity of lactic acid at this stage was $48.69 \%$ (in terms of peak area) and 1/6 in terms of number of peaks. Removal of cells, cell debris and other insoluble solid residues are performed through this step. The supernatant thus collected was subsequently subjected to Ultrafiltration process. The grossly insoluble solid-free supernatant of fermented broth after centrifugation was fed to ultrafiltration unit fitted with a 10,000 Da molecular weight cutoff membrane. Relative purity of lactic acid did not increase considerably in terms of peak area $(56.24 \%)$. However, the concentration of lactic acid in the permeate increased keeping the relative purity (1/6) almost same. This was further validated through the HPLC profile (Fig. 5).

Purification using ion exchange chromatography

Before actually performing the separation technique, it is very important to get some idea about the process parameters such as $\mathrm{pH}$ of the fermented broth, binding capacity of the anionic resin, breakthrough curve, strength of $\mathrm{HCl}$ for elution, washing capacity of cationic resin and the effect of contaminants in the fermentation broth on its lactic acid adsorption. 


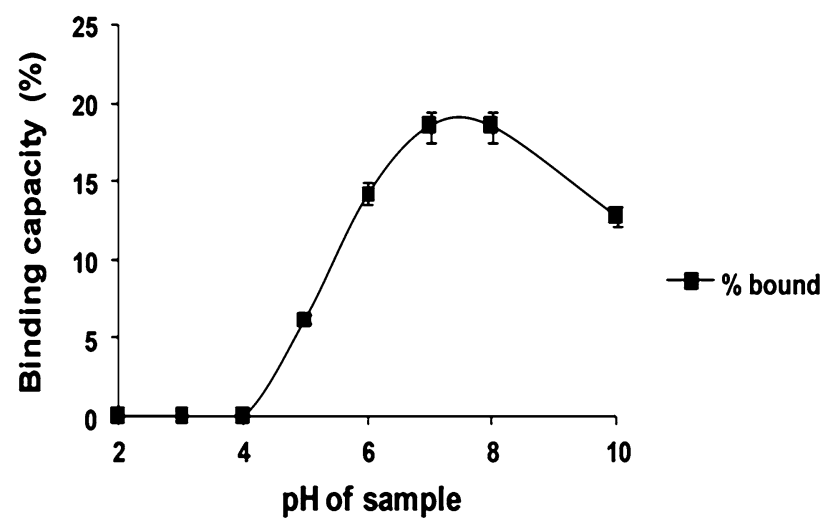

Fig. 1 Effect of $\mathrm{pH}$ on the binding of lactic acid by Amberlite IRA 96 resin. The sample was shaken for $12 \mathrm{~h}$ at the appropriate $\mathrm{pH}$ independently

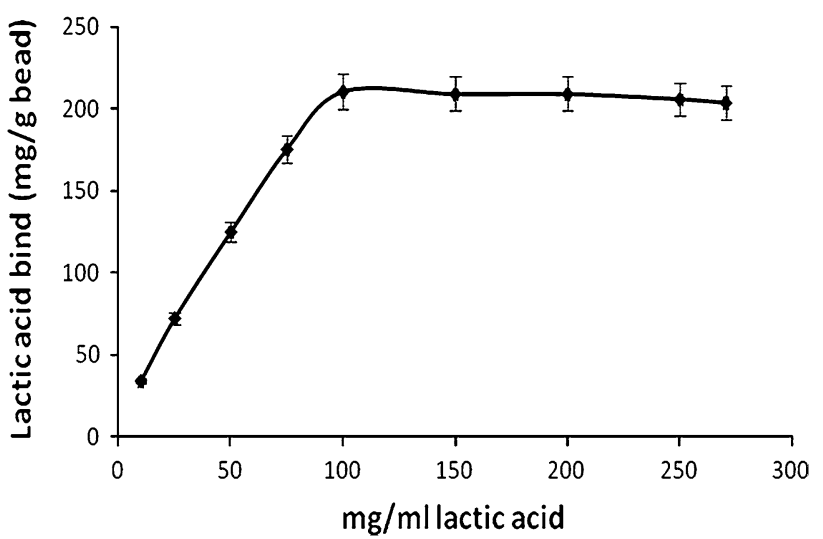

Fig. 2 Profile of binding capacity of the Amberlite IRA 96 resin at different concentrations of lactic acid. Lactic acids of appropriate concentrations were shaken for $12 \mathrm{~h}$ at $25^{\circ} \mathrm{C}$

Effect of $\mathrm{pH}$ of fermented broth on lactic acid binding

To achieve maximum adsorption efficiency, selection of the $\mathrm{pH}$ of the broth before loading it to the column is vital. It was clearly illustrated that initially from $\mathrm{pH} 2-3$ no lactic acid binding occurred (Fig. 1). As the $\mathrm{pH}$ increases, absorption also increases. $\mathrm{pH} 5$ showed maximum adsorption where $18.5 \%$ of the total lactic acid content in the fermentation broth ( $30 \mathrm{~g}$ of lactic acid in $150 \mathrm{ml}$ ) adsorbed on the beads. Further increase in $\mathrm{pH}$, however, reduced the lactic acid adsorption.

\section{Binding capacity of the resin}

The capacity of the resins to adsorb lactic acid was determined using different concentrations of lactic acid solution (Fig. 2). The result indicated gradual increase in lactic acid binding with the increasing concentration of lactic acid in the solution. At $100 \mathrm{mg} / \mathrm{mL}$ lactic acid concentration, the resins showed highest binding of lactic acid $(210.46 \mathrm{mg}$ lactic

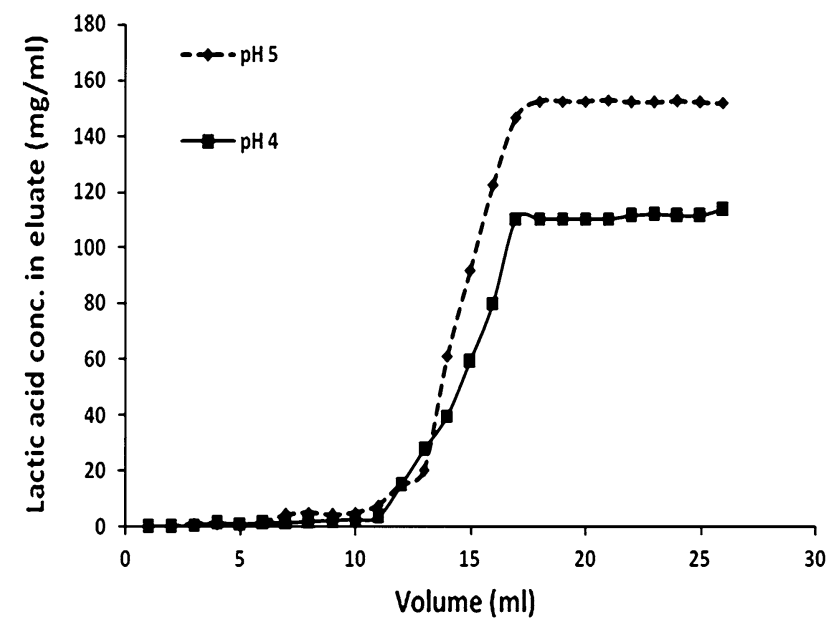

Fig. 3 Breakthrough curve at different $\mathrm{pH}$ for anion exchange resin Amberlite IRA 96 at a flow rate of $0.8 \mathrm{~mL} / \mathrm{min}$. ' $\mathrm{pH} 4$, whereas ' $\mathbf{0}$ ' represents $\mathrm{pH} 5$

acid/g bead). After which as the concentration of lactic acid increased, no significant change was observed in the binding of lactic acid.

Breakthrough curve

Breakthrough curve provided an initial step for maximizing the adsorption rate until the resin reached saturation; after that, the concentration of the target ion noticeably increased in the effluent. The breakthrough curves of $\mathrm{L}(+)$ lactic acid in fermentation broth are shown in Fig. 3. The concentration of $\mathrm{L}(+)$ lactic acid in eluate increased rapidly at elution from 15 to $22 \mathrm{~mL}$ fraction and reached a plateau after $25 \mathrm{~mL}$. The maximum adsorption capacity shown in Fig. 3 was obtained at $\mathrm{pH} 5.0$ where approximately $200 \mathrm{mg}$ lactic acid bound to $1 \mathrm{~g}$ resin. Apart from this, the curves have an S-shape.

\section{Determination of strength of $\mathrm{HCl}$}

Almost complete recovery was achieved with $\mathrm{HCl}$ from Amberlite IRA 96. The amount of lactic acid recovered against varying normality of $\mathrm{HCl}$ has been determined along with respective purity percentage (Fig. 4). Highest elution was obtained with $0.1 \mathrm{~N} \mathrm{HCl}$ showing $93.72 \%$ purity of lactic acid which decreases on further increasing the normality of $\mathrm{HCl}$. Increasing $\mathrm{HCl}$ strength further showed decrease in purity percentage. Though such enhanced purity is highly encouraging, still for its proposed application in pharmaceutical field, a higher level of purity seemed to be imperative.

\section{Cation exchange chromatography}

Though more than $90 \%$ of purity was obtained with anionic resin from the HPLC profile (Fig. 5), further 


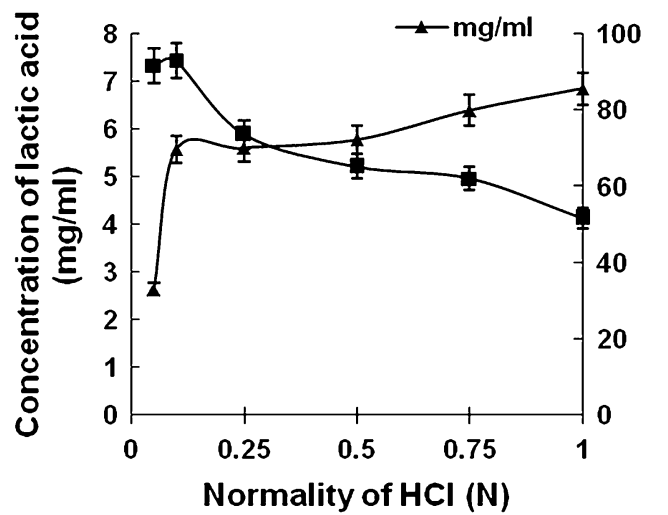

0
$\frac{0}{0}$
$\frac{0}{0}$
0
0
$\frac{0}{0}$
$\frac{0}{0}$
$\frac{0}{0}$
$\frac{2}{5}$
0
0

Fig. 4 Elution profile of lactic acid adsorbed on IRA-96 at pH 5 by various eluents ( $\mathrm{HCl}$ of different strength)

purification was attempted using cationic capacity of the resin, i.e., Amberlite IR 120. In this case, the washing capacity of the resin was determined at different $\mathrm{pH}$ of the eluate sample which showed that at $\mathrm{pH} 4$ the maximum purity of the sample was $99.17 \%$. Hence, percentage purity increased (Fig. 6) which was also shown in HPLC chromatogram (Fig. 5).

\section{Characterization of purified lactic acid}

$\mathrm{UV}-\mathrm{V}$ is spectrophotometer

The spectral structures of the UV/VIS absorption indices of lactic acid dissolved in water are very similar. The band observed in the spectra is the weak $\pi^{*} \leftarrow n$ transition of the carboxylic group of lactic acid. It is known to start close to $\sim 300 \mathrm{~nm}$ with its maximum around $260 \mathrm{~nm}$ in aqueous solutions (Maria and McGlynn 1972; Beavers 2005). In the investigated samples, the bands are slightly displaced due to conjugation, substitution and solvent effects. Figure 7 shows the absorbance in the UV-Visible region.

\section{Circular dichroism}

The stereospecificity analyzed through CD spectropolarimeter was found to be similar to the standard L-lactic acid. It showed band near $210 \mathrm{~nm}$. This absorption band is for $\alpha$ hydroxy acids. As the degree of rotation is on the positive side which is about $180^{\circ}$, it confirms the levo rotation of the sample. Circular dichroism spectroscopic graph of lactic acid has been shown in Fig. 8.

\section{Discussion}

The study illustrated the platform methodology of purification of lactic acid using fermented broth obtained from Zizyphus oenophlia. While designing the purification protocol, several interesting aspects of the process were considered, based on which studies were conducted for optimization of different condition to enhance its purity percentage. Characterization of the same purified sample was carried out to assess the feasibility of the process.

The fermented broth of lactic acid obtained from Zizyphus contains various impurities ranging from significant amount of other low-molecular weight carboxylic acids, amino acids, polyphenols, larger proteinaceous molecules,
Fig. 5 Study on a HPLC chromatogram obtained at different purification steps, b purity percentage obtained after every step of purification

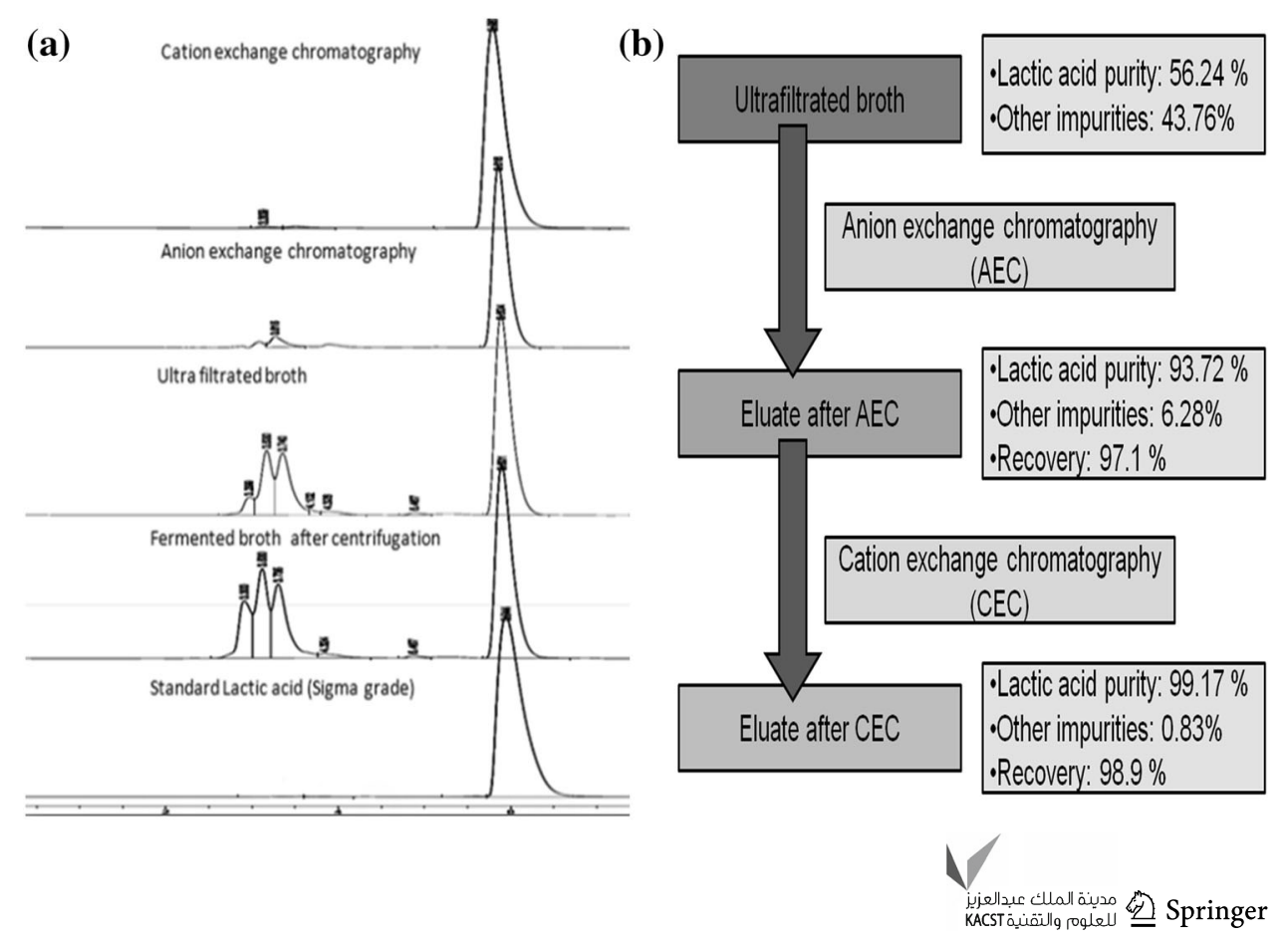




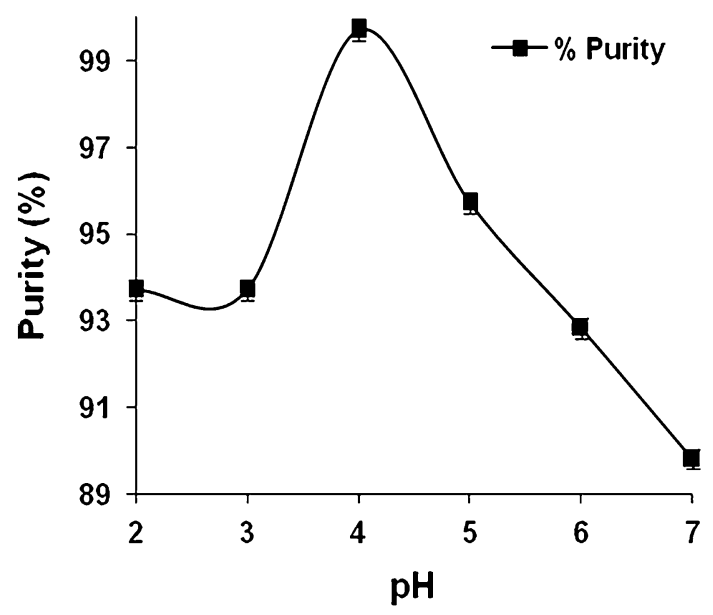

Fig. 6 Effect of different $\mathrm{pH}$ of fermented broth on washing capacity of cation exchange resin Amberlite IR 120 from pH 2 to 7

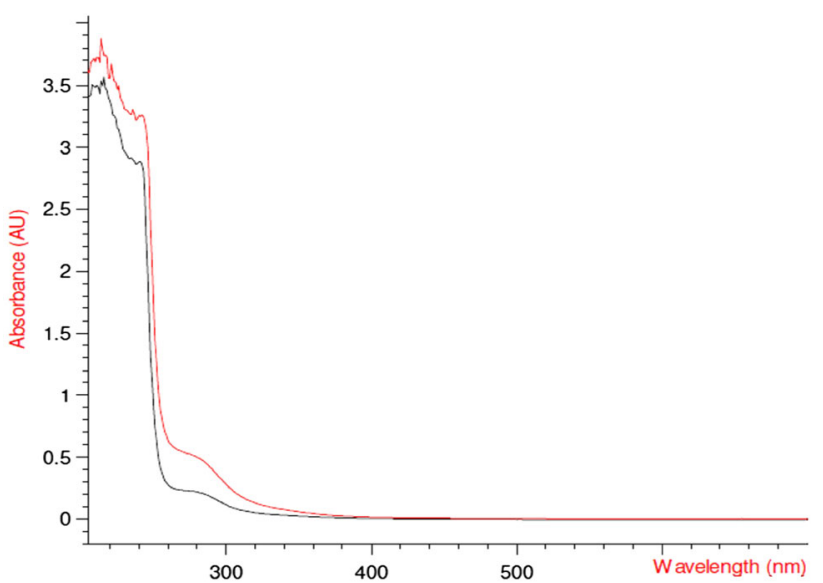

Fig. 7 UV-Vis spectrum of the purified lactic acid sample along with the pure sigma graded L-lactic acid. Here red line represents the UV scan of purified lactic acid sample and black line represents the UV scan of pure sigma graded L-lactic acid

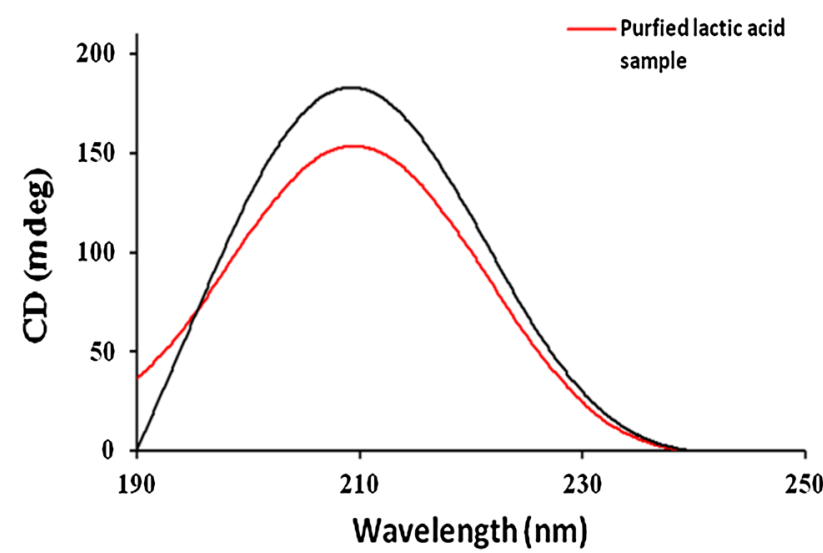

Fig. $8 \mathrm{CD}$ spectrum of the purified lactic acid sample along with the pure sigma-graded L-lactic acid where red line represents the curve of purified lactic acid sample and black line represents the curve of pure sigma-graded L-lactic acid alcohols, esters, metals, traces of sugars, unreacted carbohydrates salts, pigments, DNA, RNA and nutrients along with solid cell biomass (Groot et al. 2010). Depending on the final product specifications, the partial or total elimination of other residual ions (sulfate, phosphate) and remaining sugars (lactose, glucose) is often needed. Hence, based on the nature of contaminants, subsequent purification steps have been chosen. After initial centrifugation and ultrafiltration, a purity of $56.24 \%$ demanded further purification.

Ion exchange chromatography is the reversible adsorption of charged molecules to ion groups of opposite charge immobilized on an inert matrix. At lower $\mathrm{pH}$, the resin showed weaker affinity with the lactic acid. Probable reason of reduced binding at lower $\mathrm{pH}$ might be the drastic differences in $\mathrm{pH}$ between the resin and the sample (Tong et al. 2004). The affinity of lactic acid seemed to improve with increasing $\mathrm{pH}$. However, $\mathrm{pH}$ above 5 showed negative effect on lactic acid binding, which can be attributed to the fact that increase in the negativity of peptides, amino acids ( $\mathrm{pI}$ within the range of $\mathrm{pH}$ 5-7) and phenolics with the increasing $\mathrm{pH}$ might have caused decrease in competitive ability of lactic acid binding with the resin. Tong et al. (2004) also showed similar effect within $\mathrm{pH}$ 6-7. Another reason for which the adsorption of lactic acid is strongly affected by the initial $\mathrm{pH}$ of the sample can be due to the effect of $\mathrm{pH}$ on the equilibrium of the undissociated and dissociated acid forms (Moldes et al. 2001). Therefore, the adsorbent that will maximize the recovery of lactic acid is expected to depend on the processing $\mathrm{pH}$ as well as on the adsorbent's basicity (Moldes et al. 2003; Dechow 1989; Evangelista et al. 1994). In this regard, it has also been noticed that, with pKa of lactic acid being 3.85, below this $\mathrm{pH}$ no binding has been observed with the resin.

Amberlite IRA-96, by nature, is a weak anion exchanger. It was selected, since it does not split off amines and is important in pharmaceutical and food applications. Moreover, they are easy to regenerate, obtained in fairly pure form, and provide high recovery yield of lactic acid as compared to other resins by Chendake and Kharul (2014). The anion exchange resin Amberlite IRA 96 resins has a macroreticular structure and has maximum porosity that is higher than that of their respective gel-matrix resins. Binding of lactate ion to the ion exchange matrix predominantly occurs following the equation given below:

$\mathrm{R}^{+} \mathrm{Cl}^{-}+\mathrm{L}^{-} \rightarrow \mathrm{R}^{+} \mathrm{L}^{-}+\mathrm{Cl}^{-}$

where $\mathrm{L}$ denotes the lactate ion and $\mathrm{R}$ the overall stationary matrix containing functional group. This weak base $\mathrm{Cl}^{-}$ containing matrix was further exchanged by the counter ions, i.e., lactate ions present in the mobile phase. Initially upon regeneration, $\mathrm{R}^{+}$and $\mathrm{Cl}^{-}$remain in equilibrium within the column. As the counter charge, i.e., lactate anion is introduced in the system, the equilibrium gets shifted and the targeted ion undergoes adsorption through binding 
reversibly to the matrix with a simultaneous charge displacement of the counter ions. The overall reaction is dependent on relative affinities of the ions, concentration of the ions in solution and the $\mathrm{pH}$ of the solution. It was observed that maximum $200 \mathrm{mg}$ lactic acid/g resin got adsorbed. The results obtained showed slightly higher binding capacity of Amberlite IR 96 than that of Amberlite IR 67 as studied earlier (Chendake and Kharul (2014); Kulprathipanja 1991; Kulprathipanja and Oroskar 1991). Also, resins loaded with $\mathrm{Cl}^{-}$form during regeneration reduced the overall steps of lactic acid recovery, thus incurring the cost. Moldes et al. $(2001,2003)$ have compared four different types of Amberlite resins and finally concluded that IR 96 and 67 are weak base resins having higher binding capacity.

Generally, rapid ion exchange process with high affinity between the resin and the targeted molecules lead to steeper breakthrough curve. Comparative analysis of the slopes at different $\mathrm{pH}$ indicated an enhancement in adsorption efficiency of resin with increase in $\mathrm{pH}$. It essentially suggested that the relative affinity of lactic acid towards Amberlite IRA 96 is higher at $\mathrm{pH} 5$ as compared to the same at $\mathrm{pH} 4$, which is also in agreement with the results obtained in $\mathrm{pH}$ binding studies. The remaining curves showed a stable lactic acid concentration due to saturation in the effluent (Cao et al. 2002; Kulprathipanja and Oroskar 1991).

Dielectric constant of solvent molecules used during elution plays an important role on the interaction between the eluate and the fixed ionic groups of the resin. It is recommended to use $\mathrm{HCl}$ as the eluent because removal of the traces of $\mathrm{HCl}$ present in the final solution of lactic acid can easily be achieved owing to its relative volatility and the final product could be obtained in the form of lactic acid only rather than its corresponding salt. It is a well-known fact that retention or elution of ions adsorbed on beads is highly dependent on ionic strength or $\mathrm{pH}$ of the eluent. Hence, it might be possible that lower ionic strength $(0.1 \mathrm{~N})$ of $\mathrm{HCl}$ has enhanced the retention of the contaminating anions on the resin, as lesser number of counter ions has to compete with the analyte (Subramanian
1995; Deyl 1984). The elution was effective at this condition because selective replacement of lactate ions from the beads by $\mathrm{Cl}^{-}$ion might be preferred at that particular ionic strength of $\mathrm{HCl}$. Decrease in purity percentage attributed to the release of other contaminating anionic groups from the beads by higher strength of $\mathrm{HCl}$. This step is supposed to remove all the uncharged and basic (sugar residues, alcohols, amino acids, etc.) components resulting in almost $93 \%$ purity.

Amberlite IR-120, a strongly acidic gel resin which remains in $\mathrm{H}^{+}$form, has been showed to possess highest values of the exchange capacity by many researchers (Madzingaidzo et al. 2002; Quitero et al. 2012). It seemed to be the most promising candidate for carrying out the process. In this case, the washing capacity of the resin was determined at different $\mathrm{pH}$ of the input sample and the results showed that, at $\mathrm{pH} 4$ the maximum purity of the sample corresponds to more than $99.17 \%$. Since, the elution $\mathrm{pH}$ was higher than $\mathrm{pKa}$ value of lactic acid as well as lower than that of amino acids and phenolic acids, lactic acid might have been eluted undisturbed while the contaminants interacted with the matrix resulting in their adsorption.

The band observed in the UV/VIS spectra is the weak $\pi^{*} \leftarrow n$ transition of the carboxylic group of lactic acid. A discreet zone observed around $260 \mathrm{~nm}$ is a signature of carboxylic group. Similar observation was reported by Myhre and Nielsen (2004). Earlier study conducted by Maria and McGlynn (1972) also showed similar trend for different organic acids. This property of absorbing light below $300 \mathrm{~nm}$ wavelength was used for the determination of carboxylic group.

This absorption band at $210 \mathrm{~nm}$ is for $\alpha$-hydroxy acids. Similar kind of bands of CD spectra of lactic acid was reported earlier by Losada and Xu (2007) and Anand and Hargrea (1967) where studies were performed with different $\alpha$-hydroxy acids in different solvents. Results showed strong positive cotton effect at about $210 \mathrm{~nm}$.

A comparative data for purification of lactic acid reported by different authors have been tabulated in Table 1 from which it can be clearly depicted that the

Table 1 Comparison of the present results with the reported data on purifications for lactic acid using different ion exchange resins

\begin{tabular}{|c|c|c|c|}
\hline Ion exchangers used & Type of ion exchanger & Lactic acid purity and recovery yield & References \\
\hline Amberlite IRA 400 & Strong anion exchange resin & $94 \%$ purity & $\begin{array}{l}\text { Raya-Tonetti et al. } \\
\text { (1999) }\end{array}$ \\
\hline Amberlite IRA 92 & Weak anion exchange resin & Yield of $82.6 \%$ having purity $96.2 \%$ & Tong et al. (2004) \\
\hline Amberlite IR 120 & Strong cation exchange resin & LACTIC acid concentration of $40 \mathrm{~g} / \mathrm{dm}^{3}$ & Rincon et al. (2007) \\
\hline Amberlite IRA 67 & Weak anion exchange resin & Recovery of $92.5-98.67 \%$ of lactic acid & John et al. (2008) \\
\hline $\begin{array}{l}\text { Amberlite IRA- } 400 \text { and } \\
\text { IR-120 }\end{array}$ & $\begin{array}{l}\text { Strong anion and strong cation } \\
\text { exchange resin }\end{array}$ & Final lactic acid recovery yield was $73 \%$ & $\begin{array}{l}\text { Quintero et al. } \\
\text { (2012) }\end{array}$ \\
\hline $\begin{array}{l}\text { Amberlite IRA-96 and } \\
\text { IR-120 }\end{array}$ & $\begin{array}{l}\text { Weak anion and strong cation } \\
\text { exchange resin }\end{array}$ & $\begin{array}{l}\text { Final lactic acid recovery yield was } 96 \% \text { of purity } \\
\text { more than } 99 \%\end{array}$ & Present study \\
\hline
\end{tabular}


recovery of the present study showed an improvement on the basis of purity and recovery. The improved recovery of lactic acid has a prolonged effect on the overall economy as far as the large-scale application is concerned. Hence, present strategy confirms that a system of column packed with Amberlite IRA-96 and IR-120 could be a suitable technology for purification of fermented broth lactic acid for its application in different industries.

Hence, the present study delved into the two-step purification process using chromatographic system and the feasibility of this process for the recovery of lactic acid was investigated. Maximum binding capacity was found to $210.46 \mathrm{mg}$ lactic acid/g bead. The other parameters like binding $\mathrm{pH}, \mathrm{HCl}$ normality as eluent and loading $\mathrm{pH}$ for cation exchange process were found to be $7,0.1 \mathrm{~N}, 4$, respectively. With this simple two-step purification process, lactic acid of $99 \%$ purity was obtained. Thus, the present method of purification can be beneficial in three ways. Firstly, it provided effective means of waste reduction released from other purification processes. Secondly, straightforward downstream purification process was developed which could be economically adopted and scaled up by lactic acid industries. Finally, more than $99 \%$ pure lactic acid has been obtained which opens up frontier for its multitude application. Its characterization validated the formation of only levo rotatory form of lactic acid whose easy metabolism by the human system triggers its application towards biomaterial sector.

Acknowledgments The authors would like to acknowledge Department of Biotechnology, India for providing funds for this research.

Conflict of interest The authors declare that they have no conflict of interest in the publication.

Open Access This article is distributed under the terms of the Creative Commons Attribution License which permits any use, distribution, and reproduction in any medium, provided the original author(s) and the source are credited.

\section{References}

Anand RD, Hargrea MK (1967) The circular dichroism of s(+)-lactic acid. Chem Commun (London) 421-422. doi:10.1039/ C19670000421

Beavers EM (2005) Synthesis and characterization of lactic acidmagnesium oxide Nanocomposites: how nanoparticle size and shape effects polymerization and the resulting properties of the polymer. Dissertation, Emporia State University

Bishai M, De S, Adhikari B, Banerjee R (2013a) Copolymerization of lactic acid for cost-effective PLA synthesis and studies on its improved characteristics. Food Sci Biotechnol 22:73-77

Bishai M, De S, Adhikari B, Banerjee R (2013b) Zizyphus oenophlia: a potent substrate for lactic acid production. Bioresour Technol 133:627-629
Cao XJ, Yun HS, Koo YM (2002) Recovery of (+)-lactic acid by anion exchange resin Amberlite IRA-400. Biochem Eng J 11:189-196

Chendake YJ, Kharul UK (2014) Transport of organic acids through polybenzimidazole based membranes by 'chemodialysis'. J Membr Sci 451:243-251

Chol JI, Hong WH (1999) Recovery of lactic acid by batch distillation with chemical reactions using ion exchange resin. J Chem Eng Jpn 32:184-189

Dechow F (1989) Separation and purification techniques in biotechnology. William Andrew Publishing, New York

Deyl Z (ed.) (1984) Separation methods. In: vol. 8, New comprehensive biochemistry, Elsevier, Amsterdam

Caboche JJ, Fouache C, Choque J-C, Duflot, F, Dubois E (2000) Process for the separation and purification of lactic acid from a fermentation medium. US 6280985

Evangelista RL, Mangold AJ, Nikolov ZL (1994) Recovery of lactic acid by sorption: resin evaluation. Appl Biochem Biotechnol 45(46): 131

Gargely A, Polarimetry ORD (2000) CD Spectroscopy. In: Görög S (ed) Identification and determination of impurities in drugs. Elsivier Science, Netherland

Gonzalez MI, lvarez SA, Riera F (2007) Economic evaluation of an integrated process for lactic acid production from ultrafiltered whey. J Food Eng 80:553-561

Groot W, van Krieken J, Sliekersl O, de Vos S (2010) Production and purification of lactic acid and lactide. In: Auras R, Lim LT, Selke SEM, Tsuji H (eds) Poly(lactic acid): synthesis, structures, properties, processing, and applications. Wiley, Hoboken

Guo Q, Sun K, Feng Z, Li G, Guo M, Fan F, Li C (2012) A thorough investigation of the active titanium species in ts- 1 zeolite by in situ uv resonance raman spectroscopy. Chem Eur J 18:13854-13860. doi:10.1002/chem.201201319

John RP, Nampoothiri KM, Pandey A (2008) L (+)-Lactic acid recovery from cassava bagasse based fermented medium using anion exchange resins. Braz Arch Boil Technol 51:1241-1248

Kaufman EN, Cooper SP, Clement SL, Little MH (1995) Use of a bi particle fluidized-bed bioreactor for the continuous and simultaneous fermentation and purification of lactic acid. Appl Biochem Biotech 51(52):605-620

Kimberley AC, Taylor A (1996) A simple colorimetric assay for muramic acid and lactic acid. Appl Biochem Biotech 56:49-58

Kulprathipanja S, Oroskar AR (1991) Separation of an organic acid from a fermentation broth with an anionic polymeric adsorbent. US Patent US5068419 A, Nov 26, 1991

Losada M, Xu Y (2007) Chirality transfer through hydrogen-bonding: experimental and ab initio analyses of vibrational circular dichroism spectra of methyl lactate in water. Phys Chem Chem Phys 9:3127-3135

Madzingaidzo L, Danner H, Braun R (2002) Process development and optimization of lactic acid purification using electrodialysis. J Biotechnol 96:223-239

Maria HJ, McGlynn SP (1972) Electronic states of oxalic acid and dimethyloxalate. Absorption studies. J Mol Spectr 42:177-196

Moldes AB, Alonso JL, Parajó JC (2001) Resin selection and singlestep production and recovery of lactic acid from pretreated wood. Appl Biochem Biotechnol 95:69-81

Moldes AB, Alonso JL, Parajó JC (2003) Recovery of lactic acid from simultaneous saccharification and fermentation media using anion exchange resins. Bioprocess Biosyst Eng 25:357-363

Myhre CEL, Nielsen CJ (2004) Optical properties in the UV and visible spectral region of organic acids relevant to tropospheric aerosols. Atmos Chem Phys Discuss 4:3013-3043

Negi S, Gupta S, Banerjee R (2011) Extraction and purification of glucoamylase and protease produced by Aspergillus awamori in a single stage fermentation. Food Technol Biotech 49:310-315 
Pal P, Sikdera J, Roy S, Giorno L (2009) Process intensification in lactic acid production: a review of membrane based processes. Chem Eng Process 48:1549-1559

Quintero J, Acosta A, Mejía C, Ríos R, Torres M (2012) Purification of lactic acid obtained from a fermentative process of cassava syrup using ion exchange resins. Rev Fac Ing Univ Antioquia N 65:139-151

Raya-Tonetti G, Perotti N (1998) Expanded bed affinity chromatography using streamline-cibacron red $3 \mathrm{ba}$ for simultaneous purification of alcohol dehydrogenase and glucose-6-phosphate dehydrogenase from unclarified yeast homogenate. Latin Am Appl Res 28:89-93

Rincon J, Fuertes J, Rodriguez JF, Rodriguez L, Monteagudo JM (2007) Selection of a cation exchange resin to produce lactic acid solutions from whey fermentation broths. Solvent Extr Ion Exc 15:329-345
Sosa AV, Ochoa J, Perotti NI (2000) Modeling of direct recovery of lactic acid from whole broths by ion exchange adsorption. Bioseparation 9:283-289

Subramanian G (1995) Quality assurance in environmental monitoring: instrumental methods. VCH Publishers, Weinheim

Tong WY, Fu XY, Lee SM, Yu J, Liu JW, Wei DW, Koo YM (2004) Purification of $\mathrm{L}(+)$-lactic acid from fermentation broth with paper sludge as a cellulosic feedstock using weak anion exchanger Amberlite IRA-92. Biochem Eng J 18:89-96

Wee YJ, Kim JN, Ryu HW (2006) Biotechnological production of lactic acid and its recent applications. Food Technol Biotech 44:163-172

Zheng YZ, Ding XH, Cen PL, Yang CW, Tsao GT (1996) Lactic acid fermentation and adsorption on PVP. Appl Biochem Biotech 57(58):627-632 